\title{
Alteration of Cell Mediated Immunity in Vitiligo Patients Using Narrow Band UVB as a Treatment
}

\author{
N.F. Ibrahim(1), N.K. Radwan (1)\#, L.A. Rashed ${ }^{(2)}$ \\ ${ }^{(1)}$ Health Radiation Research Department, National Center for Radiation Research and \\ Technology (NCRRT), Atomic Energy Authority (AEA), Cairo, Egypt; (2)Biochemistry \\ Department, Cairo University, Giza, Egypt.
}

\begin{abstract}
$\mathbf{V}$ ITILIGO is considered an autoimmune depigmenting disease. There were many evidences suggested the role of $\mathrm{T}$ cell mediated immunity and cytokines in the pathogenesis of the disease. The study included 20 active vitiligo patients (group 1), 20 treated patients using narrow band ultraviolet radiation B (NBUVB) (group 2), and 20 healthy control of matching age and sex (group 3). IL- 17, IL-10, TGF- B1 levels in skin tissue were measured in the three groups using ELISA technique. The results showed a significant increase in IL- 17 and TGFB1 while there was a significant decrease in IL-10 in active vitiligo patients compared to the control $(\mathrm{P}=0.000)$. Following treatment using NB-UVB, the results showed a significant decrease in the level of both IL- 17 and TGF-B1 while there was a significant increase in IL-10 $(\mathrm{P}=0.000)$ compared to active vitiligo group. These statistically significant results suggest the cell mediated immune role in the disease and successful treatment by the narrow band UVB that altered the cytokines toxic effect.
\end{abstract}

Keywords: Vitiligo, IL-17, IL-10, TGF- B1, NB-UVB.

\section{Introduction}

Vitiligo is a depigmenting skin disease with multiple pathogenic theories. It is characterized by milky white macules with different shapes and sizes. Immune pathogenesis of the disease is not fully understood yet. There is an autoimmune destruction of melanocytes in the involved areas (Jin et al., 2012).

Generalized vitiligo is epidemiologically associated with increased prevalence of other autoimmune diseases (Picardo \&Taieb, 2010).

As a result of multiple clinical observations, vitiligo pathogenesis involves a complex linkage between multiple systems: Neural, autoimmune, genetic and redox pathways.

Abundance of cytotoxic cells in lesional and perilesional skin is a characteristic sign of the disease (Van den Boom et al., 2009).

A study by Harning et al. (1991) established the correlation between the incidence and the activity of vitiligo and cell antibodies level of the patients. Antibody-mediated, cell-mediated, and cytokine-mediated mechanisms have all accumulated supportive evidence for an autoimmune hypothesis (Harning et al., 1991). In another recent study, autoantibodies against tyrosine hydroxylase and various pigment cellsurface antigens that are specific to melanocytes have been identified in the sera of vitiligo patients (Kemp et al., 2011).

Th1, Th2, and more recently Th17 type cytokines have been significantly quantified in the sera and skin of patients with vitiligo (Kolls \& Lindén, 2004). IL-10 is a strong regulator of anti-inflammatory immune responses and is considered to be a down regulator of cytokine production by Th1 cells and macrophages (Moore et al., 2001).

More studies with carefully controlled conditions established the indispensable role of TGF-B1 in the differentiation of human Th17 cells (Volpe et al., 2008 and Yang et al., 2008).

One of the most common treatments of vitiligo around the world is a narrow band UVB

"Corresponding author email: radwanashwa@yahoo.com

DOI: 10.21608/ejrsa.2019.11066.1067

C2019 National Information and Documentation Center (NIDOC) 
phototherapy with a wavelength of $311 \mathrm{~nm}$. It is mostly used for patients with non-segmental vitiligo with affected area more than 10$20 \%$ of the body surface. Narrow band UVB phototherapy $(311 \mathrm{~nm})$ provides one of the most effective treatment modalities for vitiligo, but its mechanisms of action are not well understood (Proshutinskaia et al., 2014).

This study aims at detecting the level of IL17, IL-10 and TGF-B1 in vitiligo patients before treatment using narrow band UVB and after treatment.

\section{Materials and Method}

The present study enrolled a total of 40 subjects that included 20 active patients (mean age $29.6 \pm 6.9$ years), the same 20 patients were treated using narrow band UVB and 20 healthy controls (mean age $27.9 \pm 5.6$ years) from dermatology outpatient clinic ,Cairo University Hospital, Cairo, Egypt, in the period of April 2016 to February 2017. Approval for the study was obtained from the Institutional Ethical Committee, Cairo University, Egypt. The subjects were enrolled after providing informed consent and detailed information was obtained from all the subjects regarding demographic, clinical, and family history of vitiligo. Information was recorded in a pro forma with respect to clinical presentation of the disease, age, gender, age at onset, duration of vitiligo, family history, dietary habits, occupation, socioeconomic background, associated diseases, and clinical parameters. Vitiligo patients were treated by narrow band UVB light therapy. Patients received 28-36 sessions as a routine treatment, three times a week for three months.

\section{Exclusion criteria}

The patients enrolled were either on no drug treatment or in the washout period of three months. Patients with known allergies, other skin diseases, or other autoimmune disorders such as Hashimoto's thyroiditis, Graves' disease, type 1 insulin-dependent diabetes mellitus, Addison's disease, psoriasis, rheumatoid arthritis, and thyroid dysfunction which are known to have altered levels of cytokines, were excluded from the study.

All procedures performed in the current study involving human participants were in accordance with the ethical standards of the Research Ethical Committee (REC) of Cairo University and with the 1964 Helsinki declaration and its later amendments or comparable ethical standards.

\section{Collection and homogenization of tissues}

Skin biopsies were stored at $-80^{\circ} \mathrm{C}$ and for subsequent measurements, the tissue was homogenized in phosphate buffer saline then centrifuged at $10.000 \mathrm{rpm}$, the removed supernatant was used for cytokine analysis.

\section{Quantification of tissue cytokines}

For measurement of IL-17, TGF beta and IL-10 cytokines, the authors used the enzymelinked immunoabsorbent assay (DuoSet ELISA) capture method (R\&D System, Inc., Minneapolis, USA). This assay was performed on homogenized samples from the different groups, according to the standards described by the manufacturer. The results are expressed in $\mathrm{pg} / \mathrm{mg}$ of total protein in the assessed tissues according to the colorimetric method described by Bradford (1976).

\section{Statistical analysis}

Data was analysed using descriptive statistics to calculate the mean values, and standard deviation. Student's "t-" test, one-way ANOVA were carried out to analyse the variation between patients before and after treatment and controls. $\mathrm{P}$ - value less than 0.05 or $=0.000$ was considered statistically of a high significance.

\section{Results}

The study enlisted a total of 20 non-segmental vitiligo patients with a mean age of $31.92 \pm 17.8$ years of males (12 males), and $37 \pm 23.88$ of females ( 8 females). Those same 20 were treated using NB-UVB, and 20 healthy controls with a mean age of $32 \pm 12.67$ years of males (12 males) and $44.88 \pm 11.63$ years of females ( 8 females) were enrolled in this study. Equal numbers of males and females were chosen in both of the study groups (12 males and 8 females). The duration of the disease ranged from 1 month to 360 months in males with a mean of $64.67 \pm 98.02$ months, while in females it ranged from 1 to 120 months with a mean of $30.38 \pm 39.22$ months in females. In the present study, $50 \%$ of male and $62.5 \%$ of female patients showed active vitiligo and $50 \%$ of male patients and $37.5 \%$ of female patients showed stable vitiligo. VIDA score of patients was $0-4$ (Table 1 ). The 20 vitiligo cases 
had different VIDA scores: 5 cases scored 0, 3 cases scored 1, 4 cases scored 2, 5 cases scored 3 while 3 cases scored 4 . Family history of vitiligo was seen in $75 \%$ of male patients and $50 \%$ of female patients. As for face involvement 12 of the patients, $60 \%$ had vitiligo patches in the face. The lesions affected in the body were: Legs, arms, axilla, shoulder, hand, neck and feet. There were 6 cases with 995 body affection that included abdomen, 2 legs ,2 arms, face, and back.

In this study, IL-17, IL-10 and TGF-B1 were estimated in skin tissue of vitiligo patients and the healthy controls (Table 2). The level of IL-17 was found to be significantly higher in vitiligo patients $(133.6 \pm 32.4)$ compared to the healthy controls $(33.6 \pm 8.2)$. The difference was statistically of a high significance $(\mathrm{P}=0.000)$ (Fig. 1).
IL-10 level was found to be significantly lower in vitiligo patients $(49.3 \pm 15.2)$ compared to the healthy controls $(144.7 \pm 20.5)$. The difference was statistically of a high significance $(\mathrm{P}=0.000)$ (Fig. 2).

TGF-B1 level in skin tissue was found to be significantly higher in vitiligo patients (163.1 \pm 44.8$)$ compared to the healthy controls $(36.5 \pm 6)$. The difference was statistically of a high significance $(\mathrm{P}=0.000)$ (Fig. 3$)$.

IL-17, IL-10 and TGF-B1 levels were estimated following the treatment (Table 3 ).

The level of IL-17 was significantly lower $(86.8 \pm 21.4)$ compared to the level before treatment (133.6 \pm 32.4$)$. The difference was statistically of a high significance $(\mathrm{P}=0.000)$.

TABLE 1. Clinical data of vitiligo patients and the control group.

\begin{tabular}{|c|c|c|c|c|}
\hline & \multicolumn{2}{|c|}{ Patients $(n=20)$} & \multicolumn{2}{|c|}{ Control $(n=20)$} \\
\hline & Male $(n=12)$ & Female $(n=8)$ & Male $(n=12)$ & Female $(n=8)$ \\
\hline Mean Age & $31.92 \pm 17.8$ & $37 \pm 23.88$ & $32 \pm 12.67$ & $44.88 \pm 11.63$ \\
\hline VIDA Score & $0-4$ & $0-4$ & & \\
\hline $\begin{array}{l}\text { Range of duration of disease } \\
\text { (in months) }\end{array}$ & $1-360$ & $1-120$ & & \\
\hline $\begin{array}{l}\text { Mean of duration of disease (in } \\
\text { months) }\end{array}$ & $64.67 \pm 98.02$ & $30.38 \pm 39.22$ & & \\
\hline$\%$ Active & 50 & 62.5 & & \\
\hline$\%$ Stable & 50 & 37.5 & & \\
\hline \% Family History & 75 & 50 & & \\
\hline
\end{tabular}

TABLE 2. Comparison of IL-17, IL-10, and TGF-Bı between controls and vitiligo patients in skin tissue.

\begin{tabular}{|c|c|c|c|}
\hline & Controls (20) & Active Vitiligo (20) & P-value \\
\hline $\begin{array}{l}\mathrm{IL}-17(\mathrm{Pg} / \mathrm{ml}) \\
\text { Mean } \pm \text { SD }\end{array}$ & $33.6 \pm 8.2$ & $133.6 \pm 32.4$ & 0.000 \\
\hline $\begin{array}{l}\text { IL-10 }(\mathrm{Pg} / \mathrm{ml}) \\
\text { Mean } \pm \text { SD }\end{array}$ & $144.7 \pm 20.5$ & $49.3 \pm 15.2$ & 0.000 \\
\hline $\begin{array}{l}\text { TGF-B1 }(\mathrm{Pg} / \mathrm{ml}) \\
\text { Mean } \pm \text { SD }\end{array}$ & $36.5 \pm 6$ & $163.1 \pm 44.8$ & 0.000 \\
\hline
\end{tabular}




\section{IL-17}

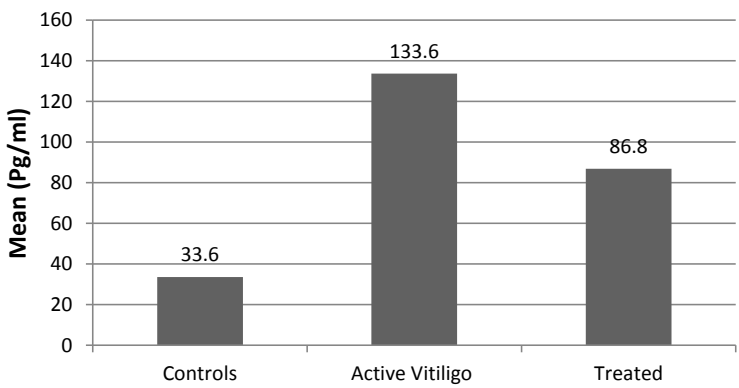

IL-10

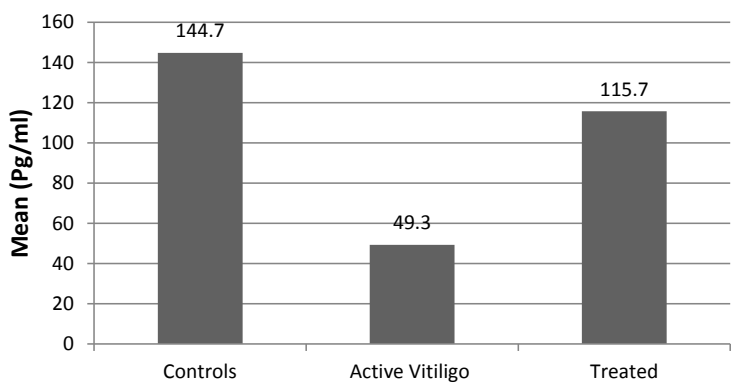

Fig. 1. Diagram showing comparison of IL-17 level in Fig. 2. Diagram showing comparison of IL-10 level in control, vitiligo patients and following treatment. control, vitiligo patients and following treatment.

TGF-B

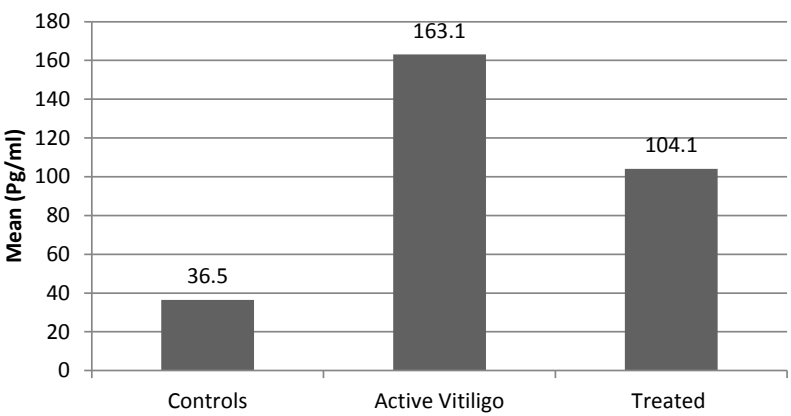

Fig . 3. Diagram showing comparison of TGF-Bı level in control, vitiligo patients and following treatment.

TABLE 3. Comparison of IL-17, IL-10, and TGF-Bı before treatment with narrow band-UVB and after treatment.

\begin{tabular}{|c|c|c|c|}
\hline & Active Vitiligo (20) & Treated (20) & P-value \\
\hline $\begin{array}{l}\mathrm{IL}-17(\mathrm{Pg} / \mathrm{ml}) \\
\mathrm{Mean} \pm \mathrm{SD}\end{array}$ & $133.6 \pm 32.4$ & $86.8 \pm 21.4$ & 0.000 \\
\hline $\begin{array}{l}\mathrm{IL}-10(\mathrm{Pg} / \mathrm{ml}) \\
\text { Mean } \pm \text { SD }\end{array}$ & $49.3 \pm 15.2$ & $115.7 \pm 29.1$ & 0.000 \\
\hline $\begin{array}{l}\text { TGF-B1 }(\mathrm{Pg} / \mathrm{ml}) \\
\text { Mean } \pm \text { SD }\end{array}$ & $163.1 \pm 44.8$ & $104.1 \pm 15.8$ & 0.000 \\
\hline
\end{tabular}

IL-10 level was found to be significantly higher in the treated vitiligo patients $(115.7 \pm 29.1)$ compared to the level before treatment $(49.3 \pm 15.2)$. The difference was statistically of a high significance $(\mathrm{P}=0.000)$.

TGF-B1 level in skin tissue was found to be significantly lower following treatment, (104.1 \pm 15.8$)$ compared to the level before treatment (163.1 \pm 44.8$)$. The difference was statistically of a high significance $(\mathrm{P}=0.000)$.

\section{Discussion}

Th17 cells were reported to be involved in the pathogenesis of many inflammatory and autoimmune disorders. For example, it was implicated to have high levels in the sera of psoriasis (Gordon, 2015; Griffiths et al., 2015 and Lebwohl et al., 2015), rheumatoid arthritis (Metawi et al., 2011), and in multiple sclerosis disease (MS) compared to the controls (Matusevicius et al., 1999). Th17 cells are known as a subset of CD4+ $\mathrm{T}$ cells that secrete various immune modulatory substances, including IL-17, 


\section{IL-21, IL-22, GM-CSF, and CCL20.}

The present study demonstrated that the level of IL-17 in skin tissue of vitiligo patients was significantly higher compared to the matching control using ELISA technique. The study of Zhou et al. (2015) revealed significantly higher serum IL-17 in 45 subjects with active nonsegmental vitiligo compared to matching control. Another two studies reported 7-fold higher levels of IL-17 on average in active vitiligo patients (Bassiouny \& Shaker, 2011 and Khan et al., 2012). Another study by Basak and his colleagues reported serum IL-17 was positively correlated with extent of body area involved (Basak et al., 2009).

Narrow band UVB light therapy is considered as an essential treatment for vitiligo patients. Following the treatment using NB- UVB, there was a significant decrease in IL-17 level $\mathrm{P}=$ 000. The same result was obtained by a study performed by Hegazy et al. They confirmed that IL-17 expression decreased by $33 \%$ lesionally and $50 \%$ perilesionally after using NB- UVB (Hegazy et al., 2014).

On the other hand, another study by Tembhre et al., noted that serum IL-17 remained higher in vitiligo patients following NB-UVB treatment compared to normal control, though those treated patients had a $7.5 \%$ reduction compared to similar untreated patients $\mathrm{P}<0.001$. Their results suggest that NB-UVB stops IL-17 secretion which may be responsible for clinical improvement of vitiligo patients following the treatment (Tembhre et al., 2013).

IL-10 is a potent regulator of anti-inflammatory immune responses so it is considered to be a down regulator of cytokine production which are the key molecules in determining autoimmune disease susceptibility and severity. The current study revealed that there was a significant decrease in IL-10 in skin of active vitiligo patients compared to the healthy controls $(\mathrm{P}=000)$.

A study by Shi and Erf reported a decrease (IL-10 level) in active vitiligo lesions (Shi \& Erf, (2012). Also, Taher et al. (2009) and Tembhre et al. (2013) reported an increased level of immunosuppressive (IL-10) in vitiligo patients who showed repigmentation process upon the treatment with tacrolimus and narrow band UVB.
The results of the present study showed that following the treatment using NB-UVB, there was a significant increase in IL-10 level compared to active vitiligo patients $(\mathrm{P}=000)$.

This observation has indicated that upregulation of IL-10 could be responsible for the clinical improvement of the treated vitilgo patients, hence it has a role in vitiligo pathogenesis.

Another study by Ala et al. reported higher IFN- $\gamma$ : IL-10 ratio compared to the healthy controls. This implies that the balance between pro- and anti- inflammatory cytokines may play an important role in the pathogenesis of nonsegmental vitiligo (Ala et al., 2015).

Astudy performed by Proshutinskaiaetal.stated that the clinical improvement was accompanied by positive changes in immunological indicators in patients' skin. They have carried out a course of narrowband UVB phototherapy $(311 \mathrm{~nm})$, which included 88 procedures. Their treatment course led to normalization of $\mathrm{CD} 8+$ and $\mathrm{CD} 1+$ cells in the epidermis of the affected skin and partial reduction of the $\mathrm{CD} 4+, \mathrm{CD} 8+$, and $\mathrm{CD} 1+$ cells content in the patients' dermis. These findings indicated that T-lymphocytes and Langerhans cells play a critical immunoregulatory role in narrow band UVB phototherapy $(311 \mathrm{~nm})$ induced immune suppression (Proshutinskaia et al., 2014).

Transforming growth factor B1 (TGF-B1) is produced by many cell types including epidermal keratinocytes. It is localized in the upper differentiated layers of the epidermis and it has an antiproliferative effect on many cell types including epidermal keratinocytes. TGF-B1 does not only have an inhibitory effect on keratinocytes, but it acts on melanocytes via specific receptors producing paracrine inhibition of human melanocyte proliferation, and melanogenesis (Hunter et al., 2007).

According to the obtained results in this study, TGF-B 1 level was significantly high in active vitiligo patients compared to the normal controls. This level was significantly decreased following the treatment with narrow band UVB.

The study by Zhou et al. (2015) on 45 nonsegmental vitiligo patients showed that there were elevated serum level of both IL-17 and TGF-B1. They reported that there was a positive correlation 
between TGF-B1and body surface area of the lesion.

Another study by Bhadwaj and colleagues on 42 active and 30 stable NSV patients showed a significant increase in the expression of IL17A, IL-1B and TGF-B that was observed in active vitiligo patients whereas no change was observed in stable patients. This suggests the possible role of these cytokines in deregulation of melanocytic activity which might be responsible for the progression of active vitiligo (Bhardwaj et al., 2017).

\section{Conclusion}

The present results show an increased IL-17 level and elevated TGF-B1, and decreased IL-10 levels in patients with NSV that can suggest their potential involvement in the development, and progression of non-segmental vitiligo (NSV). The present study with other similar studies, provide extra evidence to further understanding of the potential mechanisms of narrow band UVB and its role in controlling IL-17 cells, and related cytokines in NSV progression. This study along with other similar researches may lead to the development of more specific and effective therapies for the treatment of NSV.

Conflict of interests: The authors have no conflict of interests

\section{References}

Ala, Y., Pasha, M.K., Rao, R.N., Komaravalli, P. L. and Jahan, P. (2015) Association of IFN- $\gamma$ : IL-10 cytokine ratio with nonsegmental vitiligo pathogenesis. Autoimmune Dis. 2015, Article ID 423490 .

Basak, P.Y., Adiloglu, A.K., Ceyhan, A.M., Tas, T. and Akkaya, V.B. (2009) The role of helper and regulatory $\mathrm{T}$ cells in the pathogenesis of vitiligo. $J$. Am. Acad. Dermatol. 60, 256-60. Doi: 10.1016/j. jaad.2008.09.048.

Bassiouny, D.A. and Shaker, O. (2011) Role of interleukin-17 in the pathogenesis of vitiligo. Clin. Exp. Dermatol. 36, 292-7. Doi: 10.1111/j.13652230.2010.03972.x.

Bhardwaj, S., Rani, S., Srivastava, N., Kumar, R. and Parsad, D. (2017) Increased systemic and epidermal levels of IL-17A and IL-1 $\beta$ promotes progression of non-segmental vitiligo. Cytokine, 91, 153-161. Doi: 10.1016/j.cyto.2016.12.014.

Bradford, M.M. (1976) Rapid and sensitive method for quantitation of microgram quantities of protein utilising principle of protein dye binding. Analyt. Biochem. 72, 248-254.

Gordon, K. (2015) Ixekizumab for treatment of moderate-to-severe plaque psoriasis: 60-Week results from a double-blind phase 3 induction and randomized withdrawal study (UNCOVER-1). presented at the $73^{\text {rd }}$ Annual Meeting of the American Academy of Dermatology; March 20; 2015.

Griffiths, C.E.M., Reich, K., Lebwohl, M., van de Kerkhof, P., Paul, C. and Menter, A., et al. (2015) Comparison of ixekizumab with etanercept or placebo in moderate-to-severe psoriasis (UNCOVER-2 and UNCOVER-3): Results from two phase 3 randomised trials. Lancet. 386, 541-51. Doi: 10.1016/S0140-6736(15)60125-8.

Harning, R., Cui, J. and Bystryn, J.C. (1991) Relation between the incidence and level of pigment cell antibodies and disease activity in vitiligo. J. Invest. Dermatol. 97, 1078-80.

Hegazy, R.A., Fawzy, M.M., Gawdat, H.I., Samir, N. and Rashed, L.A. (2014) T helper 17 and Tregs: A novel proposed mechanism for NB-UVB in vitiligo. Exp. Dermatol. 23, 283-6. Doi: 10.1111/exd.12369.

Hunter, N., Kadry, D., El-Komy, M. and Aly, A. (2007) Expression of transforming growth factor beta 1 in vitiligo. Med. J. Cairo Univ. 77(3), 115-118.

Jin, y., Ferrara, T., Gowan, K., Holcomb, C., Rastrou, M., Irlich, H.A., Fain, P.R. and Spritz, R.A. (2012) Next- generation DNA re-sequencing identifies common variants of TYR and HLA-A that modulates the risk of generalized vitiligo via antigen presentation. J. Invest. Dermatol. 132 (6), 1730-1733.

Kemp, E.H., Emhemad, S., Akhtar, S., Watson, P.F., Gawkrodger, D.J. and Weetman, A.P. (2011) Autoantibodies, against. Tyrosine, hydroxylase, in patients with non-segmental (generalised) vitiligo. Exp. Dermatol. 20, 35-40. Doi: 10.1111/j.16000625.2010.01181.x.

Khan, R., Gupta, S. and Sharma, A. (2012) Circulatory 
levels of T-cell cytokines (interleukin [IL]-2, IL-4, IL-17, and transforming growth factor- $\beta$ ) in patients with vitiligo. J. Am. Acad. Dermatol. 66, 510-511. Doi: 10.1016/j.jaad.2011.07.018.

Kolls, J.K. and Lindén, A. (2004) Interleukin-17 family members and inflammation. Immunity, 21, 467-76. Doi: 10.1016/j.immuni.2004.08.018.

Lebwohl, M., Strober, B., Menter, A., Gordon, K., Weglowska, J. and Puig, L., et al. (2015) Phase 3 studies comparing brodalumab with ustekinumab in psoriasis. N. Engl. J. Med. 373, 1318-28. Doi: 10.1056/NEJMoa1503824.

Matusevicius, D., Kivisäkk, P., He, B., Kostulas, N., Ozenci, V. and Fredrikson, S., et al. (1999) Interleukin-17 mRNA expression in blood and CSF mononuclear cells is augmented in multiple sclerosis. Mult. Scler. 5, 101-4.

Metawi, S.A., Abbas, D., Kamal, M.M. and Ibrahim, M.K. (2011) Serum and synovial fluid levels of interleukin-17 in correlation with disease activity in patients with RA. Clin. Rheumatol. 30, 1201-7. Doi: 10.1007/s10067-011-1737-y.

Moore, K.W., de Waal Malefyt, R., Coffman, R.L. and O'Garra, A. (2001) Interleukin-10 and the interleukin-10 receptor. Annual Review of Immunology, 19, 683-765. Doi: 10.1146/annurev. immunol.19.1.683.

Picardo, M. and Taieb, A. (2010) "Vitiligo". Springer, New York.

Proshutinskaia, D., Volnukhin, V. and Katunina, O. (2014) Treatment of non-segmental vitiligo with narrowband UVB phototherapy $(311 \mathrm{~nm})$ : Clinical efficacy and mechanism of action. J. Clin. Exp. Dermatol. Res. 5, 6.

Shi, F. and Erf, G.F. (2012) IFN- $\gamma$, IL-21, and IL-10 coexpression in evolving autoimmune vitiligo lesions of smyth. line chickens. Journal of Investigative Dermatology, 132(3), 642-649. Doi: 10.1038/ jid.2011.377.

Taher, Z.A., Lauzon, G., Maguiness, S. and Dytoc, M.T. (2009) Analysis of interleukin-10 levels in lesions of vitiligo following treatment with topical tacrolimus. British Journal of Dermatology, 161(3), 654-659. Doi: 10.1111/j.1365-2133.2009.09217.x.

Tembhre, M.K., Sharma, V.K., Sharma, A., Chattopadhyay, P. and Gupta, S. (2013) T helper and regulatory $\mathrm{T}$ cell cytokine profile in active, stable and narrow band ultraviolet $\mathrm{B}$ treated generalized vitiligo. Clin. Chim. Acta, 424, 27-32. Doi: 10.1016/j.cca.2013.05.005.

Van den Boom, J.G., Konijnenberg, D., Dellemijn, T.A., Van der Veen, J.P., Bos, J.D., Melief, C.J., Vyth-Dreese, F.A. and Luiten, R.M. (2009) Autoimmune destruction of skin melanocytes by perilesional T cells from vitiligo patients. J. Invest. Dermatol. 129(9), 2220-32.

Volpe, E., Servant, N., Zollinger, R., Bogiatzi, S.I., Hupe, P., Barillot, E. and Soumelis, V.A. (2008) Critical function for transforming growth factorbeta, interleukin 23 and proinflammatory cytokines in driving and modulating human $\mathrm{T}(\mathrm{H})-17$ responses. Nat. Immunol. 9, 650-657.

Yang, L., Anderson, D.E., Baecher-Allan, C., Hastings, W.D., Bettelli, E., Oukka, M., Kuchroo, V.K., and Hafler, D.A. (2008) IL-21 and TGF-beta are required for differentiation of human $\mathrm{T}(\mathrm{H}) 17$ cells. Nature, 454, 350-352.

Zhou, L., Shi, Y-L., Li, K., Hamzavi, I., Gao, T-W. and Huggins, R.H., et al. (2015) Increased circulating Th17 cells and elevated serum levels of TGF-beta and IL-21 are correlated with human non-segmental vitiligo development. Pigment Cell Melanoma Res. 28, 324-9. Doi: 10.1111/pcmr.12355.

(Received 1/4/2019; accepted 10/6/2019) 
التغيرات في مناعة خلايا مرضي البهاق باستخدام الاشعه فوق البنفجيه ضيقة المدى كعلاج

نهى فوزى إبراهيم(1)، نشوة كمال رضوان(1)، ليلى أحمد راشد(2)

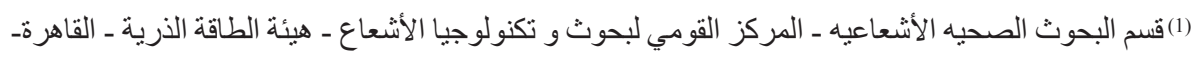
مصر، (2) قسم الكيمياء الحيويه و البيولوجيا الجزيئيه ـ كلية الطب ـ جامعة القاهرة ـ الجيزة - مصر.

البهاق هو احد امر اض المناعه الذاتيه و يتميز بعدم قدرة الخلايا على التصبغ ـ و و قد اقترحت العديد من الأدله

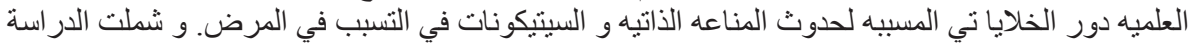

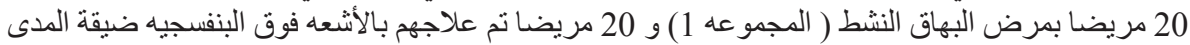

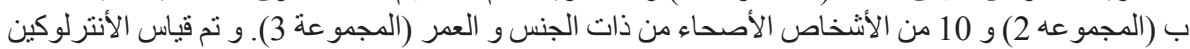

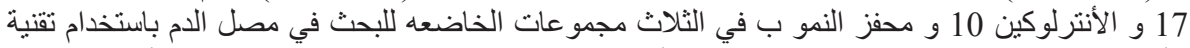

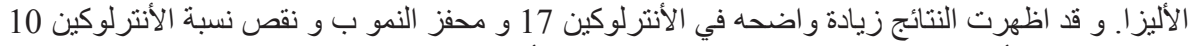

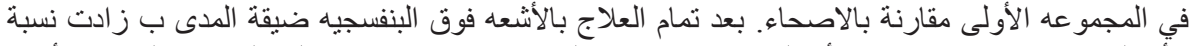

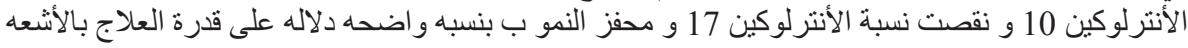
فوق البنفسجيه ب ضيقة المدي على احداث تغيير في مناعة الخلايا. 